\title{
Xanthoradones, new potentiators of imipenem activity against methicillin-resistant Staphylococcus aureus, produced by Penicillium radicum FKI-3765-2: I. Taxonomy, fermentation, isolation and biological properties
}

\author{
Hiroyuki Yamazaki $^{1}$, Kenichi Nonaka ${ }^{2}$, Rokuro Masuma ${ }^{2}$, Satoshi Ōmura ${ }^{2}$ and Hiroshi Tomoda ${ }^{1}$ \\ The fungal strain FKI-3765-2, identified as Penicillium radicum, was found to produce potentiators of imipenem activity against \\ methicillin-resistant Staphylococcus aureus (MRSA). Two new compounds, designated xanthoradones A and B, were isolated \\ from the fermentation broth of the producing strain by solvent extraction, octadecyl silyl column chromatography and preparative \\ HPLC. Xanthoradones A and B potentiated imipenem activity against MRSA by decreasing the MIC value of imipenem from \\ $16 \mu \mathrm{g} \mathrm{ml}^{-1}$ to 0.060 and $0.030 \mu \mathrm{g} \mathrm{ml}^{-1}$, respectively.
}

The Journal Antibiotics (2009) 62, 431-434; doi:10.1038/ja.2009.69; published online 24 July 2009

Keywords: fungal metabolites; imipenem potentiator; methicillin-resistant Staphylococcus aureus (MRSA); Penicillium radicum; xanthoradone; xanthoviridicatin

\section{INTRODUCTION}

Methicillin-resistant Staphylococcus aureus (MRSA), a major and widespread pathogen in hospitals, has developed resistance to many antibiotics. ${ }^{1,2}$ Moreover, MRSA is reportedly becoming resistant to the last-resort antibiotic, vancomycin, ${ }^{3}$ suggesting that resistance to vancomycin will increase in the near future. It is therefore increasingly important and necessary to find new antimicrobial agents and to devise new measures that are effective against MRSA infection.

During our continuous screening program for microbial potentiators of imipenem activity against MRSA, ${ }^{4-7}$ the culture broth of a fungal strain FKI-3765-2 was found to show potentiating activity. Activity-guided purification led to the discovery of two new compounds, namely designated xanthoradones A and B (Figure 1). They showed moderate anti-MRSA activity, but strongly enhanced imipenem activity against MRSA. The structure elucidation of xanthoradones $\mathrm{A}$ and $\mathrm{B}$ will be described in an accompanying study. ${ }^{8}$ In this study, the taxonomy of the producing strain, and fermentation, isolation and biological properties of xanthoradones are described.

\section{RESULTS}

Taxonomy of Strain FKI-3765-2

Colonies on Czapek yeast agar (CYA) after 7 days at $25^{\circ} \mathrm{C}$ (Figure 2a) were $24-25 \mathrm{~mm}$ in diameter, dense, colliculose, floccose to funiculose, with a smooth margin, and white (a) in color. The center of the colony was a dusty olive ( 1 ie) conidial color, exuding clear drops. The reverse side was golden brown (3 pg). Colonies on malt extract agar (MEA) (Figure 2b) were 19-21 mm in diameter, dense, colliculose, floccose, with a smooth margin, and light yellow (1 ea) in color, without exudate drops. The reverse side was antique gold ( $11 / 2 \mathrm{na})$. Colonies on $25 \%$ glycerol nitrate agar (G25N) (Figure 2 c) were $9.0-10 \mathrm{~mm}$ in diameter, pulvinate, floccose, with a smooth margin, and sage gray ( 24 ih), without exudate drops. The reverse side was olive (1 ni) green in color. Colonies on CYA after 7 days at $37^{\circ} \mathrm{C}$ were the same as those at $27^{\circ} \mathrm{C}$. The reverse was camel ( 3 ie) in color. The colony on CYA at $5.0^{\circ} \mathrm{C}$ showed no growth.

Conidiophores on CYA formed basal hyphae, rarely branching, were of $65-180 \times 2.5-3.0 \mu \mathrm{m}$ in size, with a smooth wall. Penicilli from conidiophores were biverticillate (consisting of metulae and phialides) (Figure 2d). Metulae were of 2-6 branches, which were usually rather appressed or sometimes slightly divergent of larger size, being 7.5$10 \times 2.3-2.7 \mu \mathrm{m}$ in size. Phialides were acerose, $12.5-15 \times 2.3-2.5 \mu \mathrm{m}$ in size, with smooth walls. Conidia were subglobose to globose, slightly roughened or sometimes smooth-walled, 2.7-3.5 (5.0) $\times 2.3-2.7 \mu \mathrm{m}$ in size and with divergent long chains (Figure 2e).

From the above-mentioned morphological characteristics, the strain FKI-3765-2 was considered to belong to genus Penicillium in the subgenus Biverticillium section Simplicia. ${ }^{9}$ Furthermore, from the characteristics of the colony colors on CYA, the rapid growth at

${ }^{1}$ Graduate School of Pharmaceutical Sciences, Kitasato University, Minato-ku, Tokyo, Japan and ${ }^{2}$ Kitasato Institute for Life Sciences, Kitasato University, Minato-ku, Tokyo, Japan Correspondence: Professor H Tomoda, Graduate School of Pharmaceutical Sciences, Kitasato University, 5-9-1 Shirokane, Minato-ku, Tokyo 108-8641, Japan. E-mail: tomodah@pharm.kitasato-u.ac.jp

Received 16 April 2009; revised 3 July 2009; accepted 3 July 2009; published online 24 July 2009 
$37^{\circ} \mathrm{C}$ on CYA and the length of conidiophores, the strain was considered to be a member of Penicillium radicum. In addition, the internal transcribed spacer (ITS) rDNA sequence (593 nucleotides) of the strain FKI-3765-2 showed $100 \%$ similarity to that of $P$. radicum (strain name) (accession no. AY256855). Thus, the producing strain FKI-3765-2 was identified as $P$. radicum.

\section{Isolation}

A thirteen-day-old rice cake $(1000 \mathrm{~g})$ was extracted with 2.01 of acetone. After the acetone extracts were filtered and concentrated to remove acetone, the aqueous solution was extracted with ethyl acetate. The extracts were dried over $\mathrm{Na}_{2} \mathrm{SO}_{4}$ and concentrated in vacuo to dryness to yield a reddish brown material $(1.8 \mathrm{~g})$. The material was dissolved in $30 \% \mathrm{CH}_{3} \mathrm{CN}$, applied to an octadecyl silyl (ODS) column $(100 \mathrm{~g})$ and eluted stepwise with $30,50,70,100 \% \mathrm{CH}_{3} \mathrm{CN}$ containing $0.050 \%$ TFA $(200 \mathrm{ml} \times 4$ tubes for each solvent, respectively). The active fractions (third and fourth tubes of $70 \% \mathrm{CH}_{3} \mathrm{CN}$ ) were concentrated in vacuo to dryness to yield a reddish brown material $(385 \mathrm{mg})$. The material was finally purified using preparative HPLC

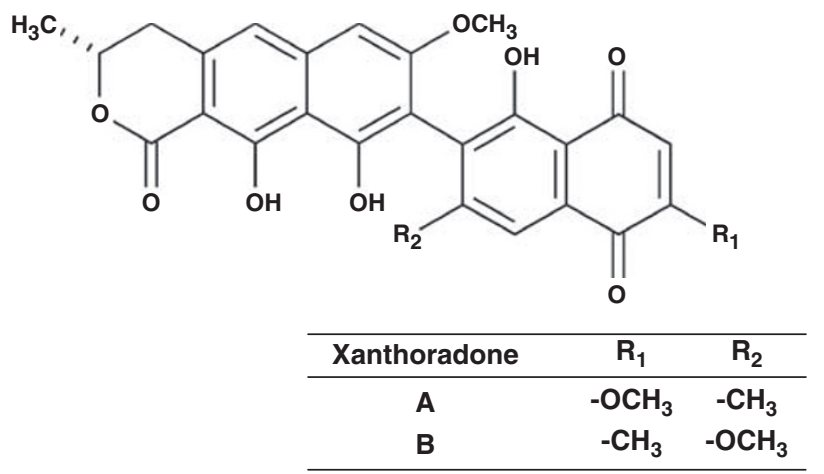

Figure 1 Structures of xanthoradones A and B. (column, PEGASIL ODS, $20 \times 250 \mathrm{~mm}$, Senshu Scientific, Tokyo, Japan; solvent, $80 \% \mathrm{CH}_{3} \mathrm{CN}$ containing $0.050 \%$ TFA; detection, UV at $210 \mathrm{~nm}$; flow rate, $\left.8.0 \mathrm{ml} \mathrm{min}^{-1}\right)$. Under these conditions, xanthoradones $\mathrm{A}$ and $\mathrm{B}$ were eluted as peaks with a retention time of 20.7 and $21.2 \mathrm{~min}$, respectively (Figure 3 ). The fractions were concentrated in vacuo to dryness to yield pure xanthoradones $\mathrm{A}(7.3 \mathrm{mg})$ and $\mathrm{B}$ $(5.6 \mathrm{mg})$ as yellow materials.

\section{Antimicrobial activity of xanthoradones}

First, the antimicrobial activity of xanthoradones was tested using the paper disc method. At a concentration of $5.0 \mu \mathrm{g}$ per disc, xanthoradone A showed inhibition zones of 8 and $9 \mathrm{~mm}$ against $S$. aureus and Bacillus subtilis, respectively. Xanthoradone B showed an inhibition zone of $9 \mathrm{~mm}$ against $B$. subtilis; however, neither xanthoradones inhibited the growth of MRSA K24 at $10 \mu \mathrm{g}$ per disc.

Second, the anti-MRSA activity of xanthoradones was tested using the liquid microdilution method. ${ }^{10}$ Xanthoradones A and B showed moderate anti-MRSA activity with an MIC of 4.0 and $2.0 \mu \mathrm{g} \mathrm{ml}^{-1}$, respectively.

Potentiation of imipenem activity against MRSA by xanthoradones Using the paper disc assay, xanthoradones A and B showed potent anti-MRSA activity with inhibition zones of 10 and $13 \mathrm{~mm}$, respectively, on agar medium A (AMA) plates containing imipenem $\left(10 \mu \mathrm{g} \mathrm{ml}^{-1}\right)$. Next, the potentiating effect of xanthoradones on the activity of imipenem and of other typical antibiotics against MRSA was investigated using the liquid microdilution method..$^{10}$ Concentrations of xanthoradones A and B were set up at 1.0 and $0.50 \mu \mathrm{g} \mathrm{ml}^{-1}$ for these experiments, respectively, which showed no effect on the growth of the MRSA K-24 strain. As summarized in Table 1, xanthoradones A and B markedly reduced the MIC value of imipenem from 16 to 0.060 and $0.030 \mu \mathrm{g} \mathrm{ml}^{-1}$, indicating a 266- and 533-fold potentiation, respectively; however, the anti-MRSA activity of streptomycin, vancomycin, tetracycline, erythromycin or ciprofloxacin was
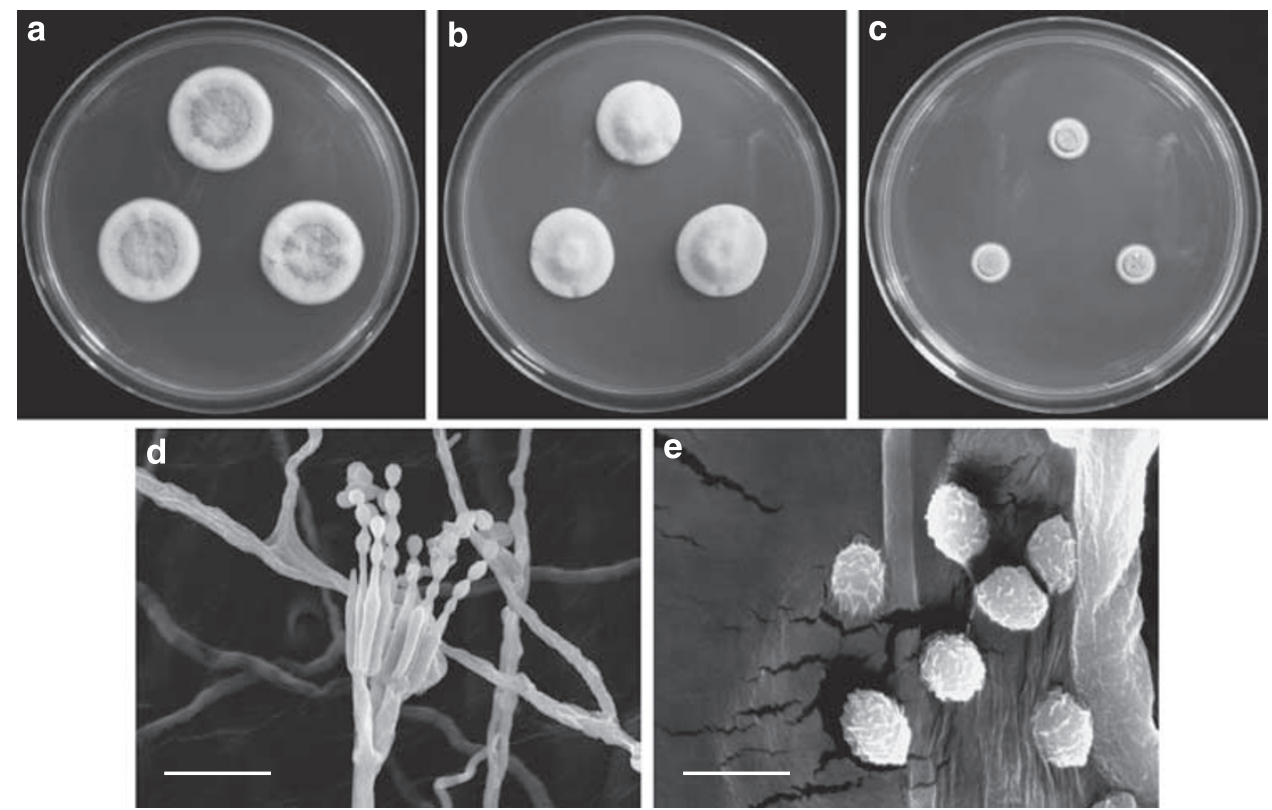

Figure 2 Morphological characteristics of xanthoradone-producing Penicillium radicum FKI-3765-2. (a) Colonies grown on Czapek yeast agar (CYA) after 7 days. (b) Colonies grown on malt extract agar (MEA) after 7 days. (c) Colonies grown on 25\% glycerol nitrate agar (G25N) after 7 days. (d) Scanning electron micrograph of conidiophores grown on MEA. Scale bar, $10 \mu \mathrm{m}$. (e) Micrograph of synnemata and conidia grown on MEA. Scale bar, $10 \mathrm{~mm}$. 


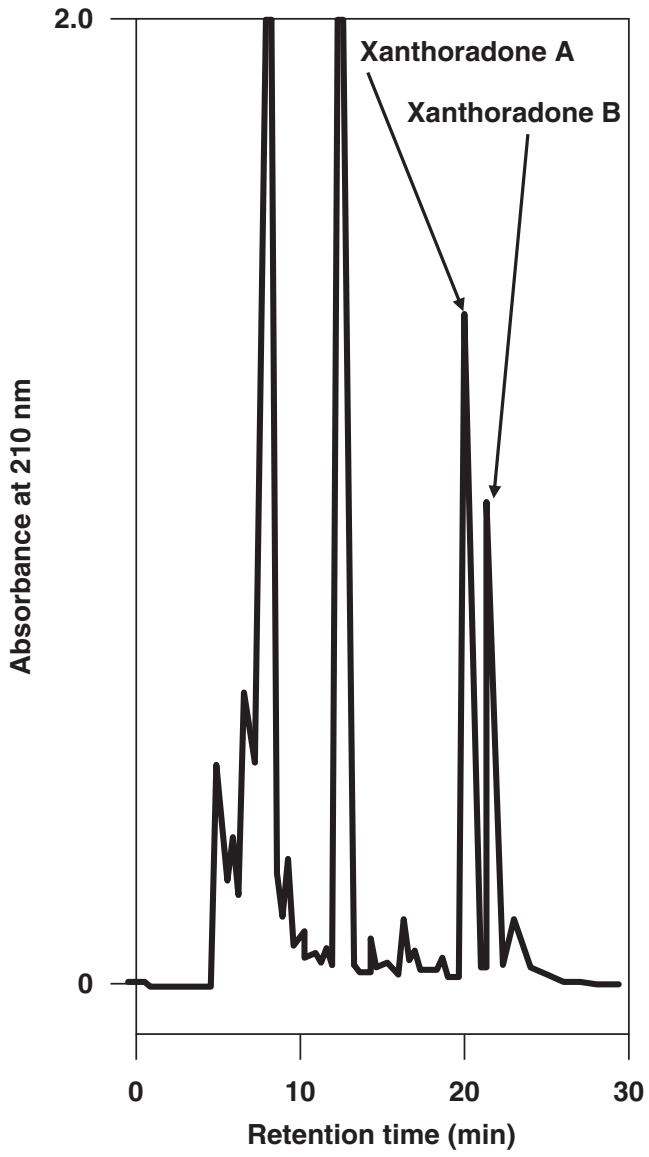

Figure 3 A chromatographic profile of xanthoradones $A$ and $B$ purification by preparative HPLC. Column, PEGASIL octadecyl silyl (ODS) $(20 \times 250 \mathrm{~mm})$; solvent, $80 \%$ aqueous acetonitrile; detection, UV at $210 \mathrm{~nm}$; flow rate, $8.0 \mathrm{ml} \mathrm{min}-1$; sample, $10 \mathrm{mg}$ of active materials (obtained through ODS column chromatography) dissolved in $200 \mu$ methanol.

Table 1 MIC of imipenem (IPM) against MRSA in the presence of xanthoradones and cytotoxic effect of xanthoradones on Jurkat cells

\begin{tabular}{lccr}
\hline & MIC of IPM & Potentiation ratio & \multicolumn{1}{c}{ C $_{50}$} \\
\cline { 2 - 4 } In combination with & $\left(\mu \mathrm{gm}^{-1}\right)$ & (None/xanthoradone) & $\mu g \mathrm{~m}^{-1}$ \\
\hline None & 16 & 1 & N.T. \\
Xanthoradone & & & \\
A & 0.060 & 266 & 23.2 \\
B & 0.030 & 533 & 2.6 \\
\hline
\end{tabular}

Abbreviation: MRSA, methicillin-resistant Staphylococcus aureus.

Concentrations of xanthoradones $A$ and $B$ are 1.0 and $0.50 \mu \mathrm{g} \mathrm{ml}^{-1}$, respectively.

not enhanced or was only slightly potentiated (twofold with streptomycin) in combination with xanthoradones (data not shown).

\section{Other biological activity}

Xanthoradones A and B showed cytotoxicity on Jurkat cells with an $\mathrm{IC}_{50}$ value of 23.2 and $2.6 \mu \mathrm{g} \mathrm{ml}^{-1}$, respectively (Table 1 ).

\section{DISCUSSION}

As described in this study, two xanthoradones (Figure 1) were isolated from the culture broth of $P$. radicum strain FKI-3765-2 and were found to potentiate imipenem inhibition against MRSA K-24. Several compounds have been reported to potentiate $\beta$-lactam activity against MRSA: polyoxotungstates, ${ }^{11}$ polyphenols such as epigallocatechin gallate isolated from tea, ${ }^{12}$ corilagin from Arctostaphylos uva-urs, ${ }^{13}$ tellimagrandin I from rose red (Rosa canina), ${ }^{13}$ diterpenes such as totarol isolated from totara tree ${ }^{14}$ and synthetic MC-200,613. ${ }^{15}$ Our research group has discovered microbial potentiators, such as stemphones from Aspergillus sp. ${ }^{4,5}$ and cyslabdan from Streptomyces sp. ${ }^{6,7}$ These potentiators have a polyphenol- or terpene-derived core structure. However, xanthoradones have a different core structure, a polyketide-derived heterodimer containing an aromatic ring.

The action mechanism of these potentiators is important for the development of a new type of anti-infective drug. ${ }^{16}$ Polyphenols and MC-200,613, as described above, were reported to affect penicillinbinding protein-2' (PBP2'). ${ }^{15,17}$ The potentiators discovered by our groups, including xanthoradones, showed no affinity to PBP2' and no effect on PBP2' expression and $\beta$-lactamase activity (data not shown); therefore, their action mechanisms seemed different from those of polyphenols and MC-200,613. Further studies are in progress.

\section{METHODS}

\section{Materials}

Vancomycin, tetracycline and ciprofloxacin were purchased from Wako Pure Chemical Industries (Osaka, Japan). Streptomycin was purchased from Meiji Seika Kaisha (Tokyo, Japan). Imipenem was purchased from Banyu Pharmaceutical (Tokyo, Japan). Erythromycin was purchased from Sigma-Aldrich (St Louis, MO, USA).

\section{Microorganisms}

The fungal strain FKI-3765-2 was isolated from a soil sample collected from Hilo, Hawaii, USA. This strain was used to produce xanthoradones. The following microorganisms were used for antimicrobial tests: B. subtilis ATCC 6633, S. aureus FDA 209P (MSSA), Micrococcus luteus PCI 1001, Escherichia coli NIHJ, Xanthomonas campestris pv. oryzae KB 88, Mucor racemosus IFO 4581 and Candida albicans KF 1. MRSA K-24 was clinically isolated in Japan.

\section{General experimental procedures}

SSC-ODS-7515-12 (Senshu Scientific) was used for ODS column chromatography. HPLC was carried out using the L-6200 system (Hitachi, Tokyo, Japan). To determine the amounts of xanthoradones A and B in culture broths, samples of ethyl acetate extracts were dissolved in methanol and analyzed using the HP1100 system (Hewlett-Packard, Palo Alto, CA, USA) under the following conditions: column, symmetry $(2.1 \times 150 \mathrm{~mm}$; Waters Corporation, Milford, MA, USA); flow rate $\left(0.20 \mathrm{ml} \mathrm{min}^{-1}\right)$; mobile phase (a 20-min linear gradient from $60 \% \mathrm{CH}_{3} \mathrm{CN}$ to $100 \% \mathrm{CH}_{3} \mathrm{CN}$ containing $0.050 \% \mathrm{H}_{3} \mathrm{PO}_{4}$ ); and detection (UV at $210 \mathrm{~nm}$ ). Under these conditions, xanthoradones A and B were eluted with retention times of 6.3 and $6.8 \mathrm{~min}$, respectively.

\section{Taxonomic study of the producing strain FKI-3765-2}

Taxonomic study of the fungal strain FKI-3765-2 was conducted according to the procedures described by Pitt. ${ }^{9}$ Morphological characteristics of the strain growing on CYA, MEA and G25N were observed under a light microscope (Vanox-S AH-2; Olympus, Tokyo, Japan) and a scanning electron microscope (JSM-5600; JEOL, Tokyo, Japan). Color names and hue numbers were determined according to the Color Harmony Manual. ${ }^{18}$ For molecular phylogenetic study, genomic DNA was extracted using the PrepMan Ultra Sample Preparation Reagent (Applied Biosystems, Foster City, CA, USA) according to the manufacturer's protocol. The rDNAITS regions, including the $5.8 \mathrm{~S}$ rDNA gene, were amplified by PCR using primers ITS1 and ITS4. ${ }^{19}$ Amplifications were performed using a PCR Thermal Cycler Dice mini Model TP100 (Takara Bio, Shiga, Japan). The amplified PCR products were purified using a QIAquick PCR DNA Purification Kit (Qiagen, Valencia, CA, USA). Sequencing reactions were directly performed using a BigDye Terminator v3.1 Cycle Sequencing Kit (Applied Biosystems), and the products were purified using a DyeEX 2.0 Spin Kit (Qiagen). DNA sequences were read on an ABI PRISM 3130 Genetic 
Analyzer (Applied Biosystems) and assembled using the programs SeqMan and SeqBuilder from the Lasergene7 package (DNAStar, Madison, WI, USA). The ITS region of the rDNA sequence was compared with the database of the National Center for Biotechnology Information, Japan. ITS was deposited in DDBJ (accession no. AB457008).

\section{Fermentation}

A slant culture of the strain FKI-3765-2 grown on LCA ( $0.10 \%$ glycerol, $0.080 \%$ $\mathrm{KH}_{2} \mathrm{PO}_{4}, 0.020 \% \mathrm{~K}_{2} \mathrm{HPO}_{4}, 0.020 \% \mathrm{MgSO}_{4} \cdot 7 \mathrm{H}_{2} \mathrm{O}, 0.020 \% \mathrm{KCl}, 0.20 \% \mathrm{NaNO}_{3}$, $0.020 \%$ yeast extract and $1.5 \%$ agar, adjusted to $\mathrm{pH} 6.0$ before sterilization) was inoculated into a $50-\mathrm{ml}$ tube containing $10 \mathrm{ml}$ of the seed medium $(2.0 \%$ glucose, $0.50 \%$ polypeptone, $0.050 \% \mathrm{MgSO}_{4} \cdot 7 \mathrm{H}_{2} \mathrm{O}, 0.20 \%$ yeast extract, $0.10 \%$ $\mathrm{KH}_{2} \mathrm{PO}_{4}$ and $0.10 \%$ agar, adjusted to $\mathrm{pH} 6.0$ before sterilization). The tube was shaken reciprocally for 3 days at $27^{\circ} \mathrm{C}$. A $1-\mathrm{ml}$ portion of the seed culture was then inoculated into a 500-ml Erlenmeyer flask (IWAKI, Tokyo, Japan) containing the production medium (50 g Italian rice; Japan Europe Trading, Tokyo, Japan). The production medium was prepared as follows; Italian rice $(50 \mathrm{~g})$ was soaked in water for $2 \mathrm{~h}$ and then collected in a colander. The sodden rice was put into a 500-ml Elenmeyer flask and sterilized by an autoclave. Fermentation was carried out at $27^{\circ} \mathrm{C}$ for 13 days under static conditions.

\section{Assay for potentiating imipenem activity against MRSA}

The assay for potentiating imipenem (or other antibiotics) activity against MRSA in combination with a sample (xanthoradones) was carried out using two methods: ${ }^{10}$ (1) The paper disc method, in which MRSA K-24 was cultured in a Mueller-Hinton broth (MHB; Sanko Junyaku, Tokyo, Japan) at $37^{\circ} \mathrm{C}$ for $20 \mathrm{~h}$ and adjusted to $1.0 \times 10^{8} \mathrm{CFU} \mathrm{m}^{-1}$. The inoculum $(100 \mu \mathrm{l})$ was spread in a plate $(10 \times 14 \mathrm{~cm}$; Eiken Chemical, Tokyo, Japan) on the respective AMA or agar medium B (AMB) containing MHB and $1.5 \%$ agar (Shimizu Shokuhin, Shizuoka, Japan) with or without imipenem $\left(10 \mu \mathrm{g} \mathrm{ml}^{-1}\right.$, which has no effect on the growth of MRSA). Paper discs (6 mm i.d.; Toyo Roshi Kaisha, Tokyo, Japan) containing various concentrations of a sample were placed on AMA and AMB and incubated at $37^{\circ} \mathrm{C}$ for $20 \mathrm{~h}$. Anti-MRSA activity was expressed as the diameter $(\mathrm{mm})$ of the inhibitory zone on the agar media. (2) Liquid microdilution method, ${ }^{10}$ in which xanthoradone A or B dissolved in $\mathrm{CH}_{3} \mathrm{OH}(5.0 \mu \mathrm{l})$ was added to prepare the final concentration of 1.0 or $0.50 \mu \mathrm{g} \mathrm{ml}^{-1}$, respectively, after MHB $(85 \mu \mathrm{l})$ was added to each well of a 96-well microplate (Corning, Corning, NY, USA). Imipenem dissolved in distilled water $(5.0 \mu \mathrm{l})$ was then added to each well at a final concentration of 0.015 to $512 \mu \mathrm{g} \mathrm{ml}^{-1}$. Finally, MRSA $(5.0 \mu \mathrm{l})$ was added at a concentration of $1.0 \times 10^{7} \mathrm{CFU} \mathrm{ml}^{-1}$. The microplates were incubated at $37^{\circ} \mathrm{C}$ for $20 \mathrm{~h}$ without shaking. MIC was defined as the lowest concentration of imipenem (or other antibiotics) in which MRSA cannot grow.

\section{Antimicrobial assay}

Antimicrobial activity against the seven microorganisms was measured using the paper disc method. Media for microorganisms were as follows: Nutrient agar (Sanko Junyaku) for B. subtilis, S. aureus, M. luteus, E. coli and X. campestris; a medium composed of glucose $1.0 \%$, yeast extract $0.50 \%$ and agar $0.80 \%$ for $M$. racemosus and C. albicans. A paper disc $(6 \mathrm{~mm}$ i.d.; Toyo Roshi Kaisha) containing $10 \mu$ g of the sample was placed on an agar plate. Bacteria, except X. campestris, were incubated at $37^{\circ} \mathrm{C}$ for $24 \mathrm{~h}$. C. albicans and X. campestris were incubated at $27^{\circ} \mathrm{C}$ for $24 \mathrm{~h}$. M. racemosus was incubated at $27^{\circ} \mathrm{C}$ for $48 \mathrm{~h}$. Antimicrobial activity was expressed as the diameter (mm) of the inhibitory zone.

\section{Cytotoxic assay}

The cytotoxicity of xanthoradones to Jurkat cells (a kind gift from $\mathrm{Dr} M$ Suganuma, CanBas, Shizuoka, Japan) was evaluated by the MTT assay. ${ }^{20}$ Cells $\left(2.0 \times 10^{4}\right.$ cells per $100 \mu \mathrm{l}$ per well) were cultured in 96 -well plates in the presence of a sample (xanthoradones) at the indicated concentrations at $37^{\circ} \mathrm{C}$ in $5.0 \% \mathrm{CO}_{2}$ atmosphere. After $48 \mathrm{~h}$ incubation, they received MTT solution ( $10 \mu \mathrm{l}$ to each well, $5.5 \mathrm{mg} \mathrm{ml}^{-1}$ in phosphate-buffered saline; SigmaAldrich) and were incubated at $37^{\circ} \mathrm{C}$ for $4 \mathrm{~h}$. A $90-\mu \mathrm{l}$ aliquot of the extraction solution (40\% (v/v) N,N-dimethylformamide, $2.0 \%(\mathrm{v} / \mathrm{v}) \mathrm{CH}_{3} \mathrm{COOH}, 20 \%$ (w/v) SDS and $0.03 \mathrm{~N} \mathrm{HCl}$ ) was added to each well, and the cells were incubated at room temperature for $2 \mathrm{~h}$. Cytotoxicity was determined by measuring the optical density at $550 \mathrm{~nm}$ using a plate reader (Elx-808; Central Scientific Commerce, Tokyo, Japan).

\section{ACKNOWLEDGEMENTS}

This work was supported by a grant-in-aid for Scientific Research (B) 21310146 (to HT) from the Ministry of Education, Culture, Sports, Science and Technology, Japan and by the Sasakawa Scientific Research Grant (to HY) from The Japan Science Society.

1 Tomasz, A. Multiple-antibiotic resistant pathogenic bacteria. N. Engl. J. Med. 330, 1247-1251 (1994).

2 Hiramatsu, K et al. Methicillin-resistant Staphylococcus aureus clinical strain with reduced vancomycin susceptibility. J. Antimicrob. Chemother. 40, 135-136 (1997).

3 Centers for Disease Control and Prevention. Staphylococcus aureus with reduced susceptibility to vancomycin-United States, 1997. MMWR Morb. Mortal. Wkly. Rep. 46, 765-766 (1997).

4 Koyama, N. et al. Stemphones, novel potentiators of imipenem activity against methicillin-resistant Staphylococcus aureus, produced by Aspergillus sp. FKI-2136. J. Antibiot. 58, 695-703 (2005).

5 Yamazaki, H., Koyama, N., Ōmura, S. \& Tomoda, H. Structure-activity relationships of stemphones, potentiators of imipenem activity against methicillin-resistant Staphylococcus aureus. J. Antibiot. 61, 426-441 (2008).

6 Fukumoto, A. et al. Cyslabdan, a new potentiator of imipenem activity against methicillin-resistant Staphylococcus aureus, produced by Streptomyces sp. K040144 I. Taxonomy, fermentation, isolation and structural elucidation. J. Antibiot. 61, 1-6 (2008).

7 Fukumoto, A. et al. Cyslabdan, a new potentiator of imipenem activity against methicillin-resistant Staphylococcus aureus, produced by Streptomyces sp. K040144 II. Biological activities. J. Antibiot. 61, 7-10 (2007).

8 Yamazaki, H., Ōmura, S. \& Tomoda, H. Xanthoradones, new potentiators of imipenem activity against methicillin-resistant Staphylococcus aureus, produced by Penicillium radicum FKI-3765-2 II. Structure elucidation. J. Antibiot. 62, 435-437 (2009).

9 Pitt, J. I. The Genus Penicillium, and its Teleomorphic States Eupenicillium and Talaromyces 1-634 (Academic Press, London, 1979).

10 Committee for Antimicrobial Susceptibility Testing Method. Standard methods of Japanese Society of Chemotherapy. Chemotherapy 38, 102-105 (1990) (in Japanese).

11 Fukuda, N., Yamase, T. \& Tajima, Y. Inhibitory effect of polyoxotungstates on the production of penicillin-binding proteins and $\beta$-lactamase against methicillin-resistant Staphylococcus aureus. Biol. Pharm. Bull 22, 463-470 (1999).

12 Zhao, W. H., Hu, Z. Q., Okubo, S., Hara, Y. \& Shimamura, T. Mechanism of synergy between epigallocatechin gallate and $\beta$-lactams against methicillin-resistant Staphylococcus aureus. Antimicrob. Agents Chemother. 45, 1737-1742 (2001).

13 Shiota, S. et al. Mechanisms of action of corilagin and tellimagrandin I that remarkably potentiate the activity of $\beta$-lactams against methicillin-resistant Staphylococcus aureus. Microbiol. Immunol. 48, 67-73 (2004).

14 Nicolson, K., Evans, G. \& O'Toole, P. W. Potentiation of methicillin activity against methicillin-resistant Staphylococcus aureus by diterpenes. FEMS Microbiol. Lett. 179, 233-239 (1999).

15 Chamberland, S. et al. MC-207,252 Abolishes PBP2a mediated $\beta$-lactam resistance in Staphylococci. Abstract in 35th Interscience Conference on Antimicrobial Agents and Chemotherapy (ICAAC). pp F138-F144 (1995).

16 Ōmura, S. Antiinfective drugs into the 21st century. Nippon Saikingaku Zasshi 54, 795-813 (1999) (in Japanese).

17 Yamase, T., Fukuda, N. \& Tajima, Y. Synergistic effect of polyoxotungstates in combination with beta-lactam antibiotics on antibacterial activity against methicillinresistant Staphylococcus aureus. Biol. Pharm. Bull 19, 459-465 (1996).

18 Jacobson, E., Granville, W. C. \& Foss, C. E. Color Harmony Manual, 4th edn (Container of America, Chicago, 1958).

19 White, T. J., Bruns, T., Lee, S. \& Taylor, J. W. Amplification and direct sequencing of fungal ribosomal RNA genes for phylogenetics. in PCR Protocols: A Guide to Methods and Applications (eds. Innis, M.A., Gelfand, R.H., Sninsky, J.J. \& White, T.J.) 315-332 (Academic Press, New York, 1990).

20 Mosmann, T. Rapid colorimetric assay for cellular growth and survival: application to proliferation and cytotoxicity assays. J. Immunol. Methods 65, 55-63 (1983). 